\title{
Differentiation of osmotic and secretory diarrhoea by stool carbohydrate and osmolar gap measurements
}

\author{
José Antonio Castro-Rodríguez, Eduardo Salazar-Lindo, Raúl León-Barúa
}

\begin{abstract}
Clinical features and laboratory tests that determine carbohydrate in faeces were evaluated to determine which was best able to distinguish between osmotic and secretory diarrhoea in infants and children. For this purpose 80 boys aged 3 to 24 months, with acute watery diarrhoea, were studied prospectively. The faecal osmolar gap (FOG) was calculated as: serum osmolarity - [2 $\times$ (faecal sodium + potassium concentration) $]$. Fifty eight patients were classified as having predominantly osmotic diarrhoea (FOG >100 mosmol/1), and 22 as having predominantly secretory diarrhoea (FOG $\leqslant 100$ mosmol/1). The two groups were comparable in their clinical features on admission, in the results of blood and urine tests, and in the evolution of their diarrhoeal illness. Evidence of steatorrhoea (by positive Sudan III test) and of acid faecal $\mathrm{pH}$ on admission were significantly more frequent in patients with osmotic diarrhoea. Mean (SD) faecal osmolarity was not significantly different between the two groups (319 (80) mosmol/1 in secretory diarrhoea $v 361$ (123) mosmol/1 in osmotic diarrhoea). Tests for reducing substances in faeces such as Benedict's test-with and without hydrolysis-and glucose strip, all showed a positive and significant association with osmotic diarrhoea $(p<0.05$, $<0.025,<0.05$, respectively). The presence of excess reducing substances (Benedict's test with hydrolysis $>++$ ) on admission was the most sensitive and specific test with the best predictive value for differentiating between the two types of watery diarrhoea.

(Arch Dis Child 1997;77:201-205)
\end{abstract}

Paediatrics and

Medicine, Universidad

Peruana Cayetano

Heredia and Instituto

de Investigación

Nutricional, Lima,

Perú

J A Castro-Rodríguez

E Salazar-Lindo

R León-Barúa

Correspondence and reprint requests to: Dr José Antonio Castro-Rodríguez, Instituto Médico Infantil, Barros Errazurriz 1919, Providencia, Santiago, Chile.

Accepted 3 May 1997 activity of the mucosa exceeds its absorption capacity. ${ }^{1}$ Diarrhoea of a predominantly osmotic basis is usually investigated by measure- ment of faecal carbohydrates; cessation of diarrhoea within 72 hours of fasting is a confirmatory feature of this pathological mechanism. ${ }^{2}$ More recently, measurement of the faecal osmolar gap (FOG) has also been used in investigating presumably osmotic diarrhoea. Some authors have tested this assumption by pretreating patients under study with antibiotics; faecal osmolarity has been reduced thus supporting this hypothesis. Initially FOG was defined as: faecal osmolarity $-[2 \times($ faecal sodium + potassium concentration)]. . $^{3-7}$

Faecal osmolarity, however, when measured directly in faeces, even immediately after evacuation, does not reflect the pathophysiology of diarrhoea, presumably because by the time faeces are passed, carbohydrates have been metabolised by colonic bacteria causing an increase in osmolarity. ${ }^{35}$ This premise has been tested by giving antibiotics to study patients. Faecal osmolarity is then reduced considerably, thus supporting this hypothesis. ${ }^{6}$ For the reasons mentioned above, measurement of serum osmolarity, instead of faecal osmolarity, has been considered more appropriate for the calculation of FOG. ${ }^{3}$ Thus FOG is defined as: serum osmolarity $-[2 \times$ (faecal sodium + potassium concentration)]. As such it is characteristically increased in osmotic diarrhoea. ${ }^{3-9}$ Several studies in adults with laxative induced persistent diarrhoea have used an arbitrary definition of osmotic diarrhoea as a mean (SD) serum value for FOG higher than $40,{ }^{4} 50,{ }^{8}$ or $100 \mathrm{mosmol} / 1$ respectively. $^{2379}$ The latter value is now the most widely accepted, ${ }^{2379}$ although it has never been validated in acute infantile diarrhoea.

FOG is regarded as helpful in differentiating between osmotic and secretory diarrhoea but it has the drawback of requiring sophisticated equipment and techniques that are not widely available in health services. ${ }^{4}{ }^{10}{ }^{11}$ It is important to be able to differentiate between these two types of diarrhoea in order to plan an effective oral rehydration therapy and dietary management in some patients, particularly when there is a need to reduce the high osmolar load offered to the gut in order to prevent diarrhoea worsening. In a previous study we found glucose malabsorption in 35\% of cases and in more than half of these it was related to failure of oral rehydration therapy. ${ }^{12}$ In this paper we describe the clinical characteristics of hospitalised Peruvian infants and children with osmotic and secretory diarrhoea (defined according to FOG). The main purpose was to 
Table 1 Clinical characteristics of study patients on admission; values are mean (SD) unless otherwise indicated

\begin{tabular}{|c|c|c|c|c|}
\hline & $\begin{array}{l}\text { Secretory } \\
\text { diarrhoea }\end{array}$ & Total & $\begin{array}{l}\text { Osmotic } \\
\text { diarrhoea }\end{array}$ & Total \\
\hline Age (months) & $10.9(5.1)$ & 22 & $10.4(4.7)$ & 58 \\
\hline Duration of diarrhoea before admission (hours) & 83 (78) & 22 & $76 \quad(45)$ & 58 \\
\hline Weight for height ${ }^{\star}$ & 93 (6) & 21 & $96 \quad(9)$ & 55 \\
\hline Weight for age ${ }^{\star}$ & $86 \quad(15)$ & 21 & $91 \quad(11)$ & 55 \\
\hline No (\%) with fevert & $14 \quad(63)$ & 22 & $36 \quad(64)$ & 58 \\
\hline No (\%) with vomiting & 17 (77) & 22 & $48 \quad(83)$ & 58 \\
\hline Stools $\dagger$ & $8.9(4.3)$ & 22 & $10.6(5.4)$ & 58 \\
\hline Median dehydration score & 5.6 & 22 & 6.2 & 58 \\
\hline No (\%) with clinical evidence of acidosis & $1 \quad(4.5)$ & 22 & $5 \quad(8.6)$ & 58 \\
\hline No (\%) with altered conciousness & $6 \quad(27)$ & 22 & 13 (22) & 58 \\
\hline No (\%) with body temperature $>37.8^{\circ} \mathrm{C}$ & $6 \quad(27)$ & 22 & $11 \quad(19)$ & 58 \\
\hline
\end{tabular}

No differences between groups were significant by $t$ tests or $\chi^{2}$ analysis.

$\star \%$ Median National Center for Health Statistics standards.

$\dagger 24$ Hours before admission.

ascertain which one of various simple routine tests that measure faecal carbohydrate content has the best performance in early prediction of the type of diarrhoea.

\section{Methods}

PATIENTS

All boys admitted to the rehydration ward of Cayetano Heredia University Hospital for treatment of acute diarrhoea over a 12 month period were considered for inclusion. Patients were included if they satisfied the following criteria: 3 to 24 months of age, three or more watery stools per day, for no longer than five days, dehydration clinically estimated as $>5 \%$, and no medical complications other than those directly related to dehydration. Dehydration score was ascertained according to World Health Organisation (WHO) standards. ${ }^{1} \mathrm{~Pa}-$ tients were excluded if they had hypovolaemic shock, their weight for length was $<3$ rd centile (according to National Center for Health Statistics standards), or if they had blood in the stools. Initially 88 patients were included in the study. Eight patients were excluded because not all test results were available. The 80 remaining patients all received the same standardised oral rehydration treatment. Treatment was divided into two phases: rehydration and maintenance. In the rehydration phase, patients received oral rehydration salts (ORSs) ad libitum for eight hours; plain water was offered whenever the patients seemed thirsty but refused to take the ORSs. Feeding any food, even mother's milk, was withheld until eight hours after admission. After eight hours the patients were re-evaluated and if dehydration persisted, rehydration was continued for four more hours. Those patients who were considered to be hydrated were advanced to the maintenance phase. In the maintenance phase patients were offered either breast feeding or half strength lactose free formula (Prosobee, Mead Johnson Laboratories; osmolarity 211 mosmol/1). The latter was given only to infants who were fully weaned. Infants older than 6 months were also given soft foods (osmolarity 203 mosmol/l). ORSs requirements were calculated every four hours on a volume/volume basis to replace the fluid lost in the watery stool, until diarrhoea had ceased. Patients who were not successfully rehydrated after eight or 12 hours or whose weight was less than that on admission were rehydrated by the intravenous route. Failure of maintenance treatment was diagnosed if signs of dehydration reappeared or if patients weighed less after eight hours than on admission. Diarrhoea was considered to have stopped when patients had two consecutive normal stool evacuations or did not pass any stools for at least 12 continuous hours.

\section{ADMISSION ASSESSMENT}

Patients fulfilling the inclusion criteria were admitted to the study and placed on metabolic beds (which allowed separate measurement of faecal and urinary output). Laboratory studies

Table 2 Laboratory values of study patients on admission; values are mean (SD) unless otherwise indicated

\begin{tabular}{|c|c|c|c|c|c|c|c|}
\hline \multirow[b]{2}{*}{ Blood } & \multicolumn{2}{|c|}{ Secretory diarrhoea } & \multirow[t]{2}{*}{ Total } & \multicolumn{2}{|c|}{ Osmotic diarrhoea } & \multirow[t]{2}{*}{ Total } & \multirow[t]{2}{*}{ p Value } \\
\hline & & & & & & & \\
\hline Packed cell volume & 0.37 & $(0.06)$ & 21 & 0.36 & $(0.05)$ & 57 & NS \\
\hline Plasma specific gravity & 1.028 & $3(0.002)$ & 22 & 1.03 & $(0.038)$ & 58 & NS \\
\hline Sodium (mmol/1) & 137.1 & $(6.3)$ & 22 & 138.1 & $(6.0)$ & 58 & NS \\
\hline Potassium $(\mathrm{mmol} / \mathrm{l})$ & 4.0 & $(1.0)$ & 22 & 3.9 & $(0.8)$ & 57 & NS \\
\hline Chloride $(\mathrm{mmol} / \mathrm{l})$ & 103.2 & $(11.6)$ & 22 & 104.9 & $(10.3)$ & 57 & NS \\
\hline Total carbon dioxide $(\mathrm{mmol} / \mathrm{l})$ & 11.2 & $(5.2)$ & 22 & 11.7 & $(5.3)$ & 57 & NS \\
\hline Serum osmolarity $(\mathrm{mosmol} / \mathrm{l})$ & 282.6 & (19.4) & 22 & 285.5 & $(15.8)$ & 58 & NS \\
\hline \multicolumn{8}{|l|}{ Urine } \\
\hline Specific gravity & 1.023 & $(0.015)$ & 19 & 1.02 & $(0.008)$ & 49 & NS \\
\hline Osmolarity (mosmol/1) & 540 & (243) & 17 & 526 & $(218)$ & 48 & NS \\
\hline Sodium $(\mathrm{mmol} / \mathrm{l})$ & 49.4 & $(81.4)$ & 17 & 26.2 & $(40.6)$ & 48 & NS \\
\hline Potassium (mmol/l) & 37.7 & $(27.3)$ & 17 & 23.0 & $(22.1)$ & 48 & NS \\
\hline \multicolumn{8}{|l|}{ Faeces } \\
\hline No (\%) with polymorphonuclear leucocytes & 5 & $(22)$ & 22 & 19 & (33) & 58 & NS \\
\hline No (\%) with microscopic fat (Sudan III) & 4 & (18) & 22 & 27 & $(47)$ & 57 & 0.0173 \\
\hline Sodium $(\mathrm{mmol} / \mathrm{l})$ & 67.4 & $(21.6)$ & 22 & 3.9 & $(14.8)$ & 58 & 0.0001 \\
\hline Potassium $(\mathrm{mmol} / \mathrm{l})$ & 44.4 & $(19.9)$ & 22 & 31.8 & $(10.2)$ & 58 & 0.0068 \\
\hline Osmolarity (mosmol/1) & 318 & $(80)$ & 20 & 361 & $(123)$ & 58 & NS \\
\hline \multicolumn{8}{|l|}{ No (\%) with glucose strip } \\
\hline$>+$ & 9 & (41) & 22 & 33 & $(58)$ & 58 & NS \\
\hline$>++$ & 2 & (9) & 22 & 18 & (31) & 58 & 0.0393 \\
\hline \multicolumn{8}{|l|}{ No (\%) with Benedict's test without hydrolysis } \\
\hline$>+$ & 12 & $(55)$ & 22 & 42 & $(72)$ & 58 & NS \\
\hline$>++$ & 4 & (18) & 22 & 26 & $(45)$ & 58 & 0.0279 \\
\hline \multicolumn{8}{|l|}{ No (\%) with Benedict's test with hydrolysis } \\
\hline$>+$ & 12 & (55) & 22 & 46 & $(81)$ & 57 & 0.0183 \\
\hline & 6 & $(27)$ & 22 & 41 & $(72)$ & 57 & 0.0003 \\
\hline \multicolumn{8}{|l|}{ No (\%) with $\mathrm{pH}$} \\
\hline$<5.5$ & 8 & (38) & 21 & 29 & (50) & 58 & NS \\
\hline$<6$ & 12 & $(57)$ & 21 & 46 & (79) & 58 & 0.0488 \\
\hline
\end{tabular}


included venous blood for micropacked cell volume, plasma specific gravity by refractometry, serum sodium and potassium by flame photometry, serum chloride concentrations by colorimetric titration, and microgasometric determination of total carbon dioxide content in serum. A stool sample was obtained by rectal catheter and tested for polymorphonuclear leucocytes using the methylene blue staining method, ${ }^{13}$ for microscopic fat in faeces by the Sudan III method, ${ }^{14}$ for reducing substances by Benedict's test, and for glucose by the glucose strip test. Faecal electrolytes and osmolarity were carried out by the methods already described for venous blood. The presence of faecal reducing substances was determined by Benedict's test with and without hydrolysis, according to the technique previously standardised at the unit ${ }^{15}$ using a semiquantitative scale of values: $0.5 \mathrm{~g} \%(+), 1 \mathrm{~g} \%(++), 1.5 \mathrm{~g} \%$ $(+++)$, and $2 \mathrm{~g} \%(++++)$. Benedict's test, after acid hydrolysis with hydrochloric acid $0.1 \mathrm{~N}$, was carried out to determine the presence of carbohydrates in faeces, which only become reducing sugars after being hydrolysed (for example sucrose). Benedict's test is widely used in many places as a cheaper and more easily available alternative to Clinitest tablets. It is regarded as reliable and accurate. ${ }^{15}$ The semiquantitative scale already described was used also. Faecal glucose was determined with semiquantitative strips (Glucose strips, Eli Lilly, Indianapolis, Indiana) using a semiquantitative scale: $1 / 10 \mathrm{~g} \%(+), 1 / 4 \mathrm{~g} \%(++), 1 / 2 \mathrm{~g} \%$ $(+++)$, and $2 \mathrm{~g} \%(++++)$. Faecal $\mathrm{pH}$ was measured using semiquantitative strips (ph, Neutralit, Merck, Darmstadt, Germany) with ranges from 5.5 to 9 with intervals of 0.5 units. Urine samples were obtained with a sterile urine collection bag. Electrolytes, osmolarity, and urine specific gravity were determined with the methods already described. FOG was defined in this study as: faecal osmolarity $-[2 \times$ (faecal sodium + potassium concentration) $].^{3-7}$

MICROBIOLOGY STUDIES

Fresh stool specimens were collected by rectal swab and transported to our microbiology laboratory. Specimens were cultivated for Salmonella sp, Shigella sp, vibrio, and Escherichia coli, by standard direct and enrichment media. Campylobacter sp were grown on sheep blood agar containing Butzler's antibiotic supplement. Yersinia sp were selectively cultured on cefsulodin-Irgasan-novobiocin agar, and Aeromonas sp on ampicillin blood agar. Rotavirus antigen identification was done with an enzyme linked immunosorbent assay, using reagents supplied by the WHO Collaborating Centre for Reference and Research, Birmingham.

Stools were emulsified in saline and examined by direct microscopy within hours after collection to determine the presence of Giardia lamblia and other parasites. Another portion of the stool specimen was preserved in merthiolate iodine formalin solution and processed by the formol ether sedimentation technique. Faecal smears from the direct and concentrated material were treated with $0.1 \mathrm{~N}$ sodium hydroxide and stained by the modified acid fast technique to determine the presence of Cryptosporidium $\mathrm{sp}$.

STATISTICAL ANALYSIS

After data cleaning, descriptive statistics were applied to determine whether the variables were normally distributed. The children were divided retrospectively into two groups depending on the FOG result. Osmotic diarrhoea was defined as FOG $>100 \mathrm{mosmol} / \mathrm{l}$ and secretory diarrhoea as FOG $\leqslant 100 \mathrm{mosmol} / \mathrm{l}^{2}{ }^{379}$ Continuous variables were compared with the $t$ test (two tailed) or non-parametric KruskalWallis tests, and discrete variables by either $\chi^{2}$ or Fisher's exact tests (two tailed), as appropriate. The Epi-Info software (V.5.00, CDDWHO, 1990) was used to store and process the data. This study was approved by the ethical committee of University Cayetano Heredia.

\section{Results}

Eighty eight patients were initially enrolled; eight were excluded because of incomplete laboratory data, thus leaving 80 patients for analysis.

In 58 patients $\mathrm{FOG}$ was $>100 \mathrm{mosmol} / \mathrm{l}$ and in $22, \leqslant 100 \mathrm{mosmol} / \mathrm{l}$. The first group was considered to have predominantly osmotic diarrhoea and the second, predominantly secretory diarrhoea.

No significant differences were found between patients with osmotic compared with secretory diarrhoea with regard to their clinical and laboratory (blood and urine) data found on admission to the study (tables 1 and 2).

Faecal fat, according to the Sudan III test, was found more often in patients with osmotic diarrhoea than in patients with secretory diarrhoea. There was no statistical difference in faecal osmolarity, nor in the presence of faecal polymorphonuclear leucocytes between groups.

Benedict's test showed differences between the groups. Patients with osmotic diarrhoea showed higher amounts of reducing substances than those with secretory diarrhoea. Faecal $\mathrm{pH}$ $<6$ had a greater association with osmotic than with secretory diarrhoea (table 2). Information related to clinical evolution and laboratory tests to determine dehydration status in the first 24 hours did not show any significant differences between osmotic diarrhoea and secretory diarrhoea (table 3 ).

Benedict's test had the better combination of values with hydrolysis $(\geqslant++)$ with a sensitivity of $72 \%$ (95\% confidence interval (CI) 60 to 80 ), specificity $73 \%$ (54 to 91 ), positive predictive value $87 \%$ ( 77 to 97 ), and negative predictive value $50 \%$ (34 to 66 ). These analyses were repeated at eight and 24 hours after admission and the results did not change.

No differences were found in the occurrence of intestinal pathogens between osmotic diarrhoea and secretory diarrhoea (table 4).

In a second part of the study, we divided patients according to the presence or absence of stool carbohydrates on admission. ${ }^{16-21}$ Two distinct groups emerged, without overlap, when a FOG value of $120 \mathrm{mosmol} / \mathrm{l}$ was chosen as the cut off. The respective mean (SD) 
Table 3 Clinical and laboratory evolution; values are mean (SD) unless otherwise indicated

\begin{tabular}{|c|c|c|c|c|}
\hline & Secretory diarrhoea & Total & Osmotic diarrhoea & Total \\
\hline Estimated dehydration degree \% & 5 & 21 & 5 & 55 \\
\hline Change in packed cell volume & $4.0(4.3)$ & 17 & $5.1(4.7)$ & 49 \\
\hline Change in plasma specific gravity & $0.0027(0.0029)$ & 18 & $0.0034(0.0023)$ & 50 \\
\hline \multicolumn{5}{|l|}{ ORS intake (ml/kg/hour) } \\
\hline Admission - 8 hours & $18.2(9.4)$ & 20 & $14.7(5.3)$ & 53 \\
\hline $8-24$ hours & $10.4(2.8)$ & 20 & $7.5(2.4)$ & 52 \\
\hline \multicolumn{5}{|l|}{ Stool output (ml/kg/hour) } \\
\hline Admission -8 hours & $6.6(3.1)$ & 19 & $5.3(2.9)$ & 52 \\
\hline $8-24$ hours & $4.8(2.4)$ & 17 & $4.7(2.4)$ & 51 \\
\hline \multicolumn{5}{|l|}{ Urine output (ml/kg/hour) } \\
\hline Admission -8 hours & $1.5(1.5)$ & 19 & $1.1(1.0)$ & 52 \\
\hline $8-24$ hours & $1.6(1.2)$ & 18 & $1.4(2.4)$ & 51 \\
\hline Total duration of diarrhoea in hospital (hours) & $70.3(6.3)$ & 19 & $64.8(6.6)$ & 53 \\
\hline \multicolumn{5}{|l|}{ No $(\%)$ of treatment failures } \\
\hline In rehydration period & $3(9)$ & 34 & $4(10)$ & 41 \\
\hline In maintenance period & $1(97)$ & 14 & $15(22)$ & 48 \\
\hline
\end{tabular}

No differences between groups were significant by $t$ tests or $\chi^{2}$ analysis.

figures were: $\mathrm{FOG}=134.8(54.6)(95 \% \mathrm{CI}$ 120.8 to 40.8$) \mathrm{mosmol} / \mathrm{l}$, in the group with stool carbohydrates positive, compared with FOG $=98.6$ (64.1) $(95 \%$ CI 68.4 to 121.8$)$ mosmol/1 when stool carbohydrates were negative $(\mathrm{p}=0.019)$ (fig 1$)$.

\section{Discussion}

Although FOG is a useful test to discriminate between secretory and osmotic diarrhoea, it requires the patient to be placed on a metabolic collection bed. Its cost and relative sophistication precludes use beyond tertiary centres. For this reason, we tried to ascertain if routine laboratory tests intended to detect the presence of carbohydrates in faeces were useful to differentiate osmotic diarrhoea from secretory diarrhoea.

We found that Benedict's test with hydrolysis $(>++)$ on admission was the most efficient test to predict osmotic diarrhoea. It had the highest sensitivity and specificity, as well as the best predictive value. This is because Benedict's test with hydrolysis measures all non-absorbed carbohydrates, including reducing and nonreducing sugars. Despite these advantages, its overall performance was not optimum.

Faecal osmolarity by itself does not differentiate secretory from osmotic diarrhoea. This corroborates the findings of other studies. ${ }^{24}$ The explanation is that in secretory diarrhoea electrolytes may be as high as the faecal osmolarity provided by the non-absorbed solutes in osmotic diarrhoea and then faecal osmolality can be increased in both conditions. ${ }^{3}$ In addition, there is the problem of bacterial metabolism. It is important to point out that we attempted to control for changes due to storage

Table 4 Enteropathogens recovered

\begin{tabular}{llllll}
\hline \multirow{2}{*}{ Organism } & \multicolumn{2}{c}{ Secretory diarrhoea } & & \multicolumn{2}{c}{ Osmotic diarrhoea } \\
\cline { 2 - 3 } \cline { 5 - 6 } & No $(\%)$ & Total & & No (\%) & Total \\
\hline Vibrio & 0 & 22 & & 0 & 58 \\
Salmonella & 0 & 22 & & 0 & 58 \\
Shigella & $2(9)$ & 22 & & $3(5)$ & 58 \\
Campylobacter jejuni & $3(14)$ & 22 & & $10(17)$ & 58 \\
Escherichia coli (EPEC serotypes) & $3(14)$ & 21 & & $19(35)$ & 58 \\
Rotavirus & $4(22)$ & 18 & & $17(33)$ & 52 \\
Others & 0 & 22 & & $3(5)$ & 58 \\
Parasites & $4(20)$ & 20 & & $4(7)$ & 57 \\
\hline
\end{tabular}

No differences between groups were significant by $t$ tests or $\chi^{2}$ analysis.

$\star$ EPEC $=$ enteropathogenic $E$ coli. at room temperature ${ }^{41011}$ by storing samples at $4^{\circ} \mathrm{C}$ to minimise bacterial degradation. We obtained samples by rectal catheter, thus avoiding contamination with urine, which could dilute, and change, osmolarity.

There was a higher concentration of faecal sodium and potassium in patients with secretory diarrhoea but this is because these variables were used in the definition of FOG that was part of the criteria applied to separate the two groups. ${ }^{3}$

We found microscopic fat in faeces more often in osmotic diarrhoea. The explanation is not clear, but faecal losses of long chain fatty acids is probably determined by the underlying cause of the diarrhoea with damage to intestinal mucosa. ${ }^{3}$ On the other hand patients with carbohydrate malabsorption can present with fat malabsorption.

We also found that faecal $\mathrm{pH}<6$ on admission was significantly more frequent in osmotic diarrhoea. The chief factor may have been carbohydrate fermentation by enteral bacteria in the caecum and colon. The organic acids thus formed-mainly acetic, propionic, butyric, and lactic - bring about a decrease in $\mathrm{pH}^{4}{ }^{5} 1022$

The frequency of faecal isolation of enteropathogens was similar in both groups. However, we did not look for enterotoxigenic $E$ coli in our study. We found more rotavirus and enteropathogenic $E$ coli in osmotic diarrhoea, as reported by other studies. ${ }^{182324}$

The cut off point in FOG values we selected to distinguish between osmotic and secretory diarrhoea, was taken from studies of adult patients. Dividing our patient group according to the presence or absence of carbohydrates in

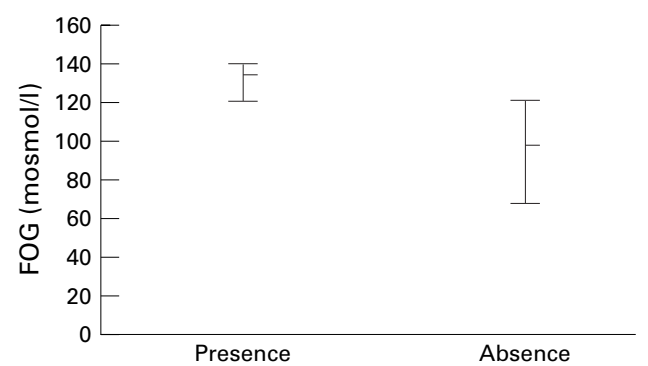

Figure 1 FOG in children according to presence or absence of stool carbohydrates at admission $(p=0.0188)$; mean, maximum, and minimum values are shown. 
stools on admission, ${ }^{16-21}$ two distinct groups emerged, without overlap, if a FOG value of $120 \mathrm{mosmol} / \mathrm{l}$ is chosen as the cut off (fig 1). Thus we suggest that a FOG cut off value of $120 \mathrm{mosmol} / 1$ may be a better indicator of carbohydrate malabsorption, and hence the presence of osmotic diarrhoea, than a cut off value of $100 \mathrm{mosmol} / \mathrm{l}$ in children. However, Benedict's test with hydrolysis $(>++)$ remains the most useful predictor of osmotic diarrhoea.

This study was supported by the National Council of Science and Technology (CONCYTEC-PERU). We would like to thank Dr Percy Miranda and Dr Miguel Campos for help with data analysis, and the advice and critical reviews provided by Dr Mary Penny and Beth Yeager from the Institute de Investigación Nutricional, Lima, Perú, and Dr Ernesto Guiraldes from the Catholic University of Chile.

1 Organización Panamericana de Salud, ed. Manual de tratamiento de la diarrea. PALTEX No 13. Washington, DC: OPS Press, 1987.

2 Ladefoged K, Schaffalitzky de Muskadell OB, Jarnum S. Faecal osmolality and electrolyte concentrations in chronic diarrhoea: do they provide diagnostic clues? Scand $\mathcal{F}$ diarrhoea: do they provide
Gastroenterol $1987 ; 22: 813-20$.

3 Krejs G, Fordtran JS. Diarrhea. In: Sleisenger MH, Fordtran JS, eds. Gastrointestinal disease. Philadelphia: WB Fordtran JS, eds. Gastrointe

4 Shiau YF, Feldman G, Resnick M, Coff P. Stool electrolyte and osmolality measurements in the evaluation of diarrhea disorders. Ann Intern Med 1985;102:773-5

5 Wrong D, Metcalfe-Gibson A. The electrolyte content of faeces. Proc R Soc Med 1975;70:864-6.

6 Wilson DR, Ing TS, Metcalfe-Gibson A, Wrong DM. In vivo dialysis of feces as a method of stool analysis: III. The effect of intestinal antibiotics. Clin Sci 1968;34:211-21.

7 Johnson DA, Cattan E. Stool chemistries in patients with unexplained dirrhea. Am Fam Physician 1986;33:131-4.

8 Read NW, Krejs G, Read M, Santa Ana C, Morawski S, Fordtran JS. Chronic diarrhea of unknown origin. Gastroenterology 1980;78:264-71.

9 Morris A, Turnberg LA. Surreptitious laxative abuse. Gorris A, Turnberg LA. Sur
Gastroenterology 1979;77:780-6.

10 Hammer H, Santa Ana L, Schiller L, Fordtran JS. Studies of osmotic diarrhea induced in normal subjets by ingestion of polyethylene glycol and lactulose. 7 Clin Invest 1989;84: 1056-62.

11 Penney MD, Walters G. Are osmolality measurements clinically useful? Ann Clin Biochem 1987;24:566-71.

12 Salazar-Lindo E, Sack B, Chea-Woo E, León-Barúa R, Kay $\mathrm{B}, \mathrm{Yi} \mathrm{A}$. Bicarbonate versus citrate in oral rehydration theraphy in infants with watery diarrhea. A controlled clinical trial. F Pediatr 1986;108:55-60

13 Aguilar J. Investigacion de leucocitos fecales en enfermedad diarreica aguda infantil. Correlacion clínica y valores estacionales. [Tesis Bachiller Medicina.] Lima: Universidad cionales. [Tesis Bachiller Medicina.]

14 Alvarez M. Diagnóstico de la esteatorrea por el método microscopico de Sudan III y el método bioquímico de Van de Kamer. [Tesis Licenciatura Biologia.] Lima: Universidad Particular Ricardo Palma, 1987: 78.

15 Saavedra J. Estudio sobre la intolerancia a los carbohidratos detectada aplicando el método de Benedict's en infantes con enfermedad diarrica aguda. [Tesis Bachill con enfermedad diarreica aguda. [Tesis Bachiller Medicina.] Lima: Universidad Peruana Cayetano Heredia,
1981: 87.

16 Lifshitz F, Coello-Ramirez P, Gutierrez-Topete G, Cornado-Cornet $M$. Carbohydrate intolerance in infants with diarrhea. F Pediatr 1971;79:760-7.

17 Lifshitz C, Irving C, Gopalakrishma G, Evans K, Nichols B. Carbohydrate malabsorption in infants with diarrhea studied with the breath hydrogen test. F Pediatr 1983;102:3715.

18 Fagundes-Neto V, Viaro T, Lifshitz F. Tolerance to glucose polymers in malnurished infants with diarrhea and
disaccharide intolerance. Am f Clin Nutr 1985;41:228-34.

19 Coello-Ramirez P, Lifshitz F. Enteric microflora and carbohydrate intolerance in infants with diarrhea. Pediatrics 1972;49:233-42.

20 Lifshitz F, Coello-Ramirez P, Contreras Gutierrez ML. The response of infants to carbohydrate oral loads after recovery from diarrhea. 7 Pediatr 1971;79:612-7.

21 Maffei HV, Daher SR, Moreira FL. Carbohydrate malabsorption in infants with diarrhea: diagnostic and evolutive aspects. Arq Gastroenterol 1984;21:136-42.

22 Torres-Pinedo R, Lavastida M, Rivera L, Rodríguez H, Ortiz A. Studies on infant diarrhea. I. A comparison of milk-feeding and intravenous therapy upon the composition and volume of the stool and urine. F Clin Invest 1966; 45:469-80.

23 Sack D, Rhoads M, Molla A, Molla AM, Wahed M. Carbohydrate malabsoption in infants with rotavirus diarrhea. Am f Clin Nutr 1982;36:1112-8.

24 Velasquez-Jones L, Rodríguez R. Bacterial induced diarrhoea. Drugs 1988;36(suppl 4):617. 